\title{
Evaluation of Shear Strength and Cone Penetration Resistance Behavior of Tropical Silt Loam Soil under Uni-Axial Compression
}

\author{
Seth I. Manuwa*, Omolola C. Olaiya \\ Department of Agricultural Engineering, School of Engineering and Engineering Technology, The Federal University of Technology, \\ Akure, Nigeria. \\ Email: *sethimanuwa@yahoo.com
}

Received March 29 ${ }^{\text {th }}$, 2012; revised April 30 ${ }^{\text {th }}$ 2012; accepted May $14^{\text {th }}, 2012$

\begin{abstract}
Laboratory investigations were conducted to study strength characteristics of silt loam soil of Ilorin, Kwara State, Nigeria, under uni-axial compression tests. The main objective of this study was to evaluate the effects of applied pressure and moisture content on strength indices such as bulk density, penetration resistance and shear strength of the soil and to develop relationships between the strength indices for predictive purposes necessary in soil management. The compression was carried out at different moisture contents determined according to the consistency limits of the soil. The applied pressure ranged from 75 to $600 \mathrm{kPa}$. Values of bulk density, penetration resistance and shear strength increased with increase in moisture content up to peak values after which the values decreased with further increase in moisture content. Regression models were used to describe the trends in the results for the soil. Results also showed that bulk density and soil strength normally regarded as indicators of soil quality are affected by moisture content and applied pressure and that these properties can be predicted using the models generated from the study.
\end{abstract}

Keywords: Loamy Soils; Applied Pressure; Bulk Density; Penetration Resistance; Moisture Content; Shear Strength; Nigeria

\section{Introduction}

Soil strength has been regarded as important characteristics that affect many aspects of agricultural soils, such as the performance of cultivation implements, root growth, least-limiting water range and trafficabilty [1]. They further reported that characterization of soil strength is usually made by measuring the response of a soil to a range of applied forces.

Soil compaction may be defined as the densification of unsaturated soil due to reduction in air volume without change in mass wetness [2]. Soil compaction occurs in unsaturated soils when subjected to mechanical forces [3]. While soil compaction is essential in many engineering works (especially civil engineering) it is undesirable in agricultural production to a large extent. Compaction reduces the soil permeability to water, so that run off and erosion may occur and adequate recharge of ground water is prevented. Compaction reduces regeneration of the soil, so that metabolic activities of roots are impaired. Compaction increases the mechanical strength of the soil, so root growth is impeded. It is known that in agricultural

${ }^{*}$ Corresponding author. system, the risk of soil compaction increases with the growth of farm size, increased mechanization and equipment weight, and the drive for greater productivity. Soil compaction also has negative effects on the environment by increasing runoff and erosion thereby accelerating potential pollution of surface water by organic wastes and applied agrochemicals [4]. All of these effects may reduce the quality and quantity of food and fiber grown on the soil. Therefore, the knowledge of soil compaction is increasingly important and desirable within agriculture and environmental protection.

The state of soil compactness is expressed in several ways: bulk density (expressed on a wet or dry basis), porosity and apparent specific gravity [5]. Accurate compaction behavior equations will provide a means to predict compaction. The ability to predict compaction is the first requirement for attaining control of compaction. Considerable research has been performed in attempts to develop soil compaction behaviour equations [6-12]. Others have also reported on effects of organic matter and tractor passes on compaction and yield of crops [13,14].

The aim of this study therefore was to observe the behavior of Ilorin silty loam soils under uni-axial compres- 
sion as it is affected by applied pressure and water content and also to model the behavior using regression analysis for the purpose of prediction.

\section{Materials and Methods}

\subsection{Site of Soil Sample}

The soil sample was taken from the arable soils of National Centre for Agricultural Mechanization (NCAM) Ilorin, Kwara State, Nigeria (8.30 N 4.32 E). The soil was Regosols (FAO). The soil samples were collected from the first $35 \mathrm{~cm}$ of soil profile; each sample was dug to a radius of $15 \mathrm{~cm}$ and then mixed thoroughly to get a homogeneous mixture, and then taken to the laboratory for further processing and analysis

\subsection{Analytical Methods}

Particle size analysis of the soils was performed using hydrometer method [16]. Organic matter content of the soils was determined using the [16] method. Other physical and chemical properties of the soils were also determined using standard methods.

\subsection{Compression Test}

The samples that collected were each air-dried and ground to pass through a $2-\mathrm{mm}$ sieve. The moisture levels for compaction tests were chosen according to the consistency limits of the soils determined by the procedure described by [15]. Compaction test was performed by filling the proctor mould with a known mass of soil and placed under a uni-axial compression apparatus (Universal Testing Machine (UTM), manufactured by the Testometric Co. Ltd., UK). Compression was carried out at a steady speed of $30 \mathrm{~mm} / \mathrm{min}$. Soil samples in the mould were subjected to $75,100,150,200,300,400,500,600$ $\mathrm{kPa}$. The soil displacement and mass were recorded for each compaction. The mass was used to calculate bulk density of compacted soil sample. The proctor mould was $16.8 \mathrm{~cm}$ height and $10 \mathrm{~cm}$ diameter. A circular thick metal plate was placed on the compression end of the UTM to effect uniform compaction in the proctor mould. After each compaction test, the change in depth of compressed soil was measured with the aid of a digimatic vernier caliper.

\subsection{Cone Index Measurement}

Cone index (CI) was determined using a Rimick CP20 recording penetrometer (model CP 20 ultrasonic, Agridry Rimik Pty Ltd, Toowoomba), with a standard $30^{\circ}$ cone of $322-\mathrm{mm}^{2}$ base area and a penetration rate was less than $10 \mathrm{~mm} / \mathrm{s}$. Measurements were taken at two depths 5 and $10 \mathrm{~cm}$ of the proctor mould and the average of the read- ings taken as the representative value of cone index at that treatment.

\subsection{Shear Strength Measurement}

The shear strength of the soil was observed using a 19 $\mathrm{mm}$ vane of a shear vane tester. Measurements were taken at two depths of 5 and $10 \mathrm{~cm}$ and the average recorded to represent the shear strength of the particular treatment.

\section{Results and Discussion}

\subsection{Soil Physical Properties}

The soil studied was a silty loam soil according to the USDA textural classification of soils. Table 1 shows some physical and chemical properties of the soil. The consistency limits of the soils are also presented in Table 1. Plasticity index is an index of workability of the soil and a large range of plasticity index implies a need for large amounts of energy to work the soil to a desired tilth.

\subsection{Soil Strength Properties}

Shear strength and cone index are indicators of soil strength. Shear strength is the resistance of soil to shearing or structural failure. The shear strength of an individual clod decreases with wetting, but more importantly, the strength of the bulk soil increases with increasing

Table 1. Some physical and chemical properties of experimental soil.

\begin{tabular}{|c|c|}
\hline Property & Values \\
\hline Sand (\%) & 22.6 \\
\hline Silt (\%) & 62.8 \\
\hline Clay (\%) & 14.5 \\
\hline Silt + clay (\%) & 77.3 \\
\hline Texture (\%) & Silt loam \\
\hline Organic carbon (g/kg) & 2.03 \\
\hline Organic matter (\%) & 3.51 \\
\hline Total nitrogen (g/kg) & 0.18 \\
\hline pH in $\mathrm{H}_{2} \mathrm{O}(1: 2)$ & 7.93 \\
\hline $\mathrm{Ca}^{2+}(\mathrm{cmol} / \mathbf{k g})$ & 0.17 \\
\hline $\mathrm{Mg}^{2+}(\mathrm{cmol} / \mathbf{k g})$ & 1.70 \\
\hline $\mathrm{Na}^{+}(\mathrm{cmol} / \mathrm{kg})$ & 0.17 \\
\hline $\mathrm{K}^{+}(\mathrm{cmol} / \mathrm{kg})$ & 0.29 \\
\hline$P(\mathbf{m g} / \mathbf{k g})$ & 4.00 \\
\hline Plastic limit (\%) & 9.2 \\
\hline Liquid limit (\%) & 40 \\
\hline Plasticity index & 30.8 \\
\hline
\end{tabular}


moisture up to the lower plastic limit at which each particle is surrounded by a film of water which acts as lubricant. Soil strength drops sharply from that point to the upper plastic limit, where the soil becomes viscous.

The effects of moisture content and applied pressure on shear strength of the experimental soils are presented in Figure 1. Shear strength increased with increase in moisture content up to a maximum and then decreased as the moisture content of the soil further increased. This is a typical soil behavior which has been reported by other researchers. The peak value occurred at higher moisture content as the applied pressure increased. The maximum shear strength of the soils at applied pressure of $600 \mathrm{kPa}$ was $1025 \mathrm{kPa}$ at moisture content of $9.1 \%(\mathrm{db})$. Similarly, the effects of moisture content and applied pressure on cone index of the soils are presented in Figure 2. The relationship is similar to that exhibited by shear strength. The maximum cone index at applied pressure of $600 \mathrm{kPa}$ was $1325 \mathrm{kPa}$ at moisture content of 5.0\% (db).

However, the effects of moisture content and applied pressure on bulk density showed behavior that was different from those of shear strength and cone index (Figure 3 ).

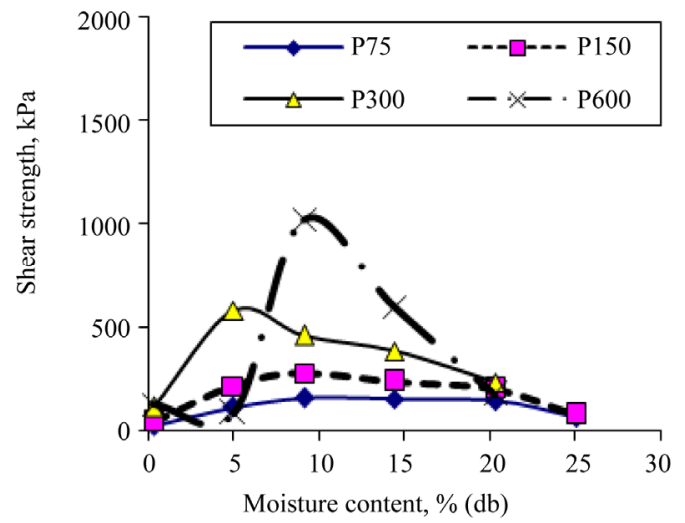

Figure 1. Effect of moisture content and applied pressure on shear strength.

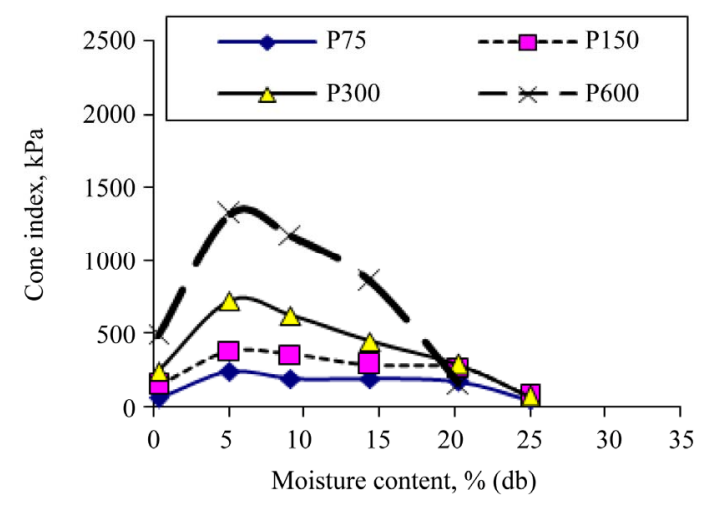

Figure 2. Effect of moisture content and applied pressure on cone index.

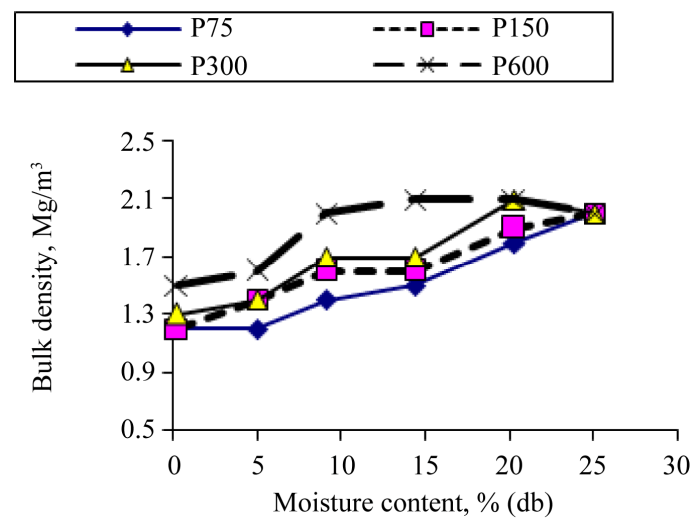

Figure 3. Effect of moisture content and applied pressure on bulk density.

Regression models (Table 3) were also established to show relationships between compaction indices such as shear strength, cone index and bulk density at applied pressures of 75, 300 and $600 \mathrm{kPa}$ representing a range of low to medium and high pressures. The relationships vary from linear to exponential and to polynomial functions.

The results also found a linear correlation between cone index and shear strength at a low applied pressure of $75 \mathrm{kPa}$. This agrees well with the findings of Vanags et al. [1] who reported linear relationship between cone index and surface shear resistance of soil.

Bulk density decreased at higher moisture content after the peak value because further addition of water created greater water pressure which reduced soil compressibility. The maximum bulk density at applied pressure of 600 $\mathrm{kPa}$ was $2.1 \mathrm{Mg} / \mathrm{m}^{3}$ at $15.0 \%(\mathrm{db})$. This moisture content was significant because it was the moisture content at which the soil reached maximum bulk density. This agrees with other researchers' report that soils with high amount of fine particles (clay plus silt) are more susceptible to compactability [17].

The regression models that describe the behavior of soil parameters shown in Figures $\mathbf{1}$ to $\mathbf{3}$ are presented in Table 2. The models are largely nonlinear and they agree well with those reported by other researchers [6-12].

\section{Conclusions}

The following conclusions can be drawn from this study.

1) The study showed that compaction behavior of silt loam soil can be modeled after certain linear and nonlinear regression equations.

2) Cone index have good positive linear relationship with shear strength, but can also be fitted with polynomial (quadratic) function with higher coefficient of determination.

3) The effect of moisture content and applied pressure 
Table 2. Relationships between dependent and independent variables.

\begin{tabular}{cccccc}
\hline $\begin{array}{c}\text { Dependent } \\
\text { variables }\end{array}$ & $\begin{array}{c}\text { Independent } \\
\text { variables }\end{array}$ & Predictive models & $\mathbf{R}^{2}$ & Applied pressure, kPa & Model type \\
\hline SS & MC & $y=-0.797 x^{2}+21.77 x+21.63$ & 0.9733 & 75 & polynomial \\
SS & MC & $y=-1.384 x^{2}+35.46 x+52.5$ & 0.9394 & 150 & polynomial \\
SS & MC & $y=-2.54 x^{2}+55.09 x+191.1$ & 0.7899 & 300 & polynomial \\
SS & MC & $y=-3.875 x^{2}+97.17 x+39.08$ & 0.468 & 600 & polynomial \\
CI & MC & $y=-1.056 x^{2}+25.1 x+83.75$ & 0.8061 & 75 & polynomial \\
CI & MC & $y=-1.53 x^{2}+34.2 x+177.3$ & 0.8384 & 150 & polynomial \\
CI & MC & $y=-2.63 x^{2}+52.79 x+342.1$ & 0.7914 & 300 & polynomial \\
CI & MC & $y=-4.543 x^{2}+82.54 x+698.9$ & 0.729 & 600 & polynomial \\
BD & MC & $y=1.133 e^{0.022 x}$ & 0.9661 & 75 & exponential \\
BD & MC & $y=31.4 x+1228.7$ & 0.9624 & 150 & linear \\
BD & MC & $y=32.02 x+1304.5$ & 0.8976 & 300 & linear \\
BD & MC & $y=-0.001 x^{2}+0.059 x+1.395$ & 0.9442 & 600 & Polynomial \\
\hline
\end{tabular}

$\mathrm{C}=$ cone index; $\mathrm{BD}=$ bulk density; $\mathrm{MC}$ = moisture content; $\mathrm{SS}$ = shear strength.

Table 3. Relationships between cone index, shear strength and bulk density.

\begin{tabular}{|c|c|c|c|c|c|}
\hline $\begin{array}{c}\text { Dependent } \\
\text { variables }\end{array}$ & $\begin{array}{c}\text { Independent } \\
\text { variables }\end{array}$ & Predictive models & $\mathbf{R}^{2}$ & Applied pressure, kPa & Model type \\
\hline CI & SS & $y=1.184 x+24.52$ & 0.6651 & 75 & linear \\
\hline CI & SS & $y=0.0006 x^{2}+0.97 x+60.5$ & 0.7914 & 150 & polynomial \\
\hline CI & SS & $y=177.59 \mathrm{e}^{0.0025 x}$ & 0.9687 & 300 & exponential \\
\hline CI & SS & $y=0.001 x^{2}-1.406 x+866.8$ & 0.2600 & 600 & polynomial \\
\hline CI & $\mathrm{BD}$ & $y=-0.0014 x^{2}+4.42 x-3108.8$ & 0.8094 & 150 & polynomial \\
\hline CI & $\mathrm{BD}$ & $y=-0.0017 x^{2}+5.30 x-3108.8$ & 0.4531 & 300 & polynomial \\
\hline CI & $\mathrm{BD}$ & $y=-10128 x^{2}+36518 x-31362$ & 0.7790 & 600 & polynomial \\
\hline
\end{tabular}

$\mathrm{CI}=$ cone index; $\mathrm{BD}=$ bulk density; $\mathrm{MC}$ = moisture content; $\mathrm{SS}$ = shear strength.

on cone index, shear strength was best fitted with polynomial function of the second order.

4) The effect of applied pressure and moisture content on bulk density of silt loam can be modeled after linear, exponential and polynomial regression functions.

\section{Acknowledgements}

The authors wish to acknowledge the good gestures of the management of the National Centre for Agricultural Mechanization (NCAM), Ilorin, Nigeria for allowing us to use their laboratory facility for this study.

\section{REFERENCES}

[1] C. Vanags, B. Minasny and A. B. McBratney, "The Dynamic Penetrometer for Assessment of Soil Mechanical Resistance," 2004.

http://www.regional.org.au/au/asssi/supersoil2004/s14/po ster/1565_vanagsc.htm

[2] H. Hillel, "Soil and Water: Physical and processes," Academic Press, New York, 1971.

[3] W. R. Gill and G. E. Van den Berg, "Soil Dynamics in Tillage and Traction," Handbook 316, Agricultural Research Service, US Department of Agriculture, Washington DC, 1968.

[4] S. Assouline, "Modeling Soil Compaction under Uniaxial Compression," Soil Science Society of America Journal, Vol. 66, No. 6, 2002, pp. 1784-1787. doi:10.2136/sssaj2002.1784

[5] A. J. Koolen and H. Kuipers, "Agricultural Soil Mechanics,” Springer-Verlag, New York, 1983, pp. 171-280. doi:10.1007/978-3-642-69010-5

[6] A. J. Koolen, "A method of Soil Compatibility Determination,” Journal of Agricultural Engineering Research, Vol. 19, No. 3, 1974, pp. 271-278. doi:10.1016/0021-8634(74)90066-3

[7] W. E. Larson, S. C. Gupta and R. A. Useche, "Compres- 
sion of Agricultural Soils from Eight Soil Orders," Soil Science Society of America Journal, Vol. 44, 1980, pp. 450-457.

doi:10.2136/sssaj1980.03615995004400030002x

[8] G. R. Saini, T. L. Chow and I. Ghanen, "Compatibility Indexes of Some Agricultural Soils of New Brunswick, Canada,” Soil Science, Vol. 137, 1984, pp. 33-38. doi:10.1097/00010694-198401000-00005

[9] S. C. Gupta and R. R. Allmaras, "Models to Assess the Susceptibility of Soil to Compaction," Advances in Soil Science, Vol. 6, 1987, pp. 65-100. doi:10.1007/978-1-4612-4682-4_2

[10] K. C. Oni, "Traffic Compaction and Tillage Effects on the Performance of Maize in Sandy loam Soil of Nigeria," Agricultural Mechanization in Asia, Africa and Latin America, Vol. 22, No. 2, 1991, pp. 27-31.

[11] C. W. Smith, M. Johnston and A. Lorentz, "Assessing the Compaction Susceptibility of South African Forestry Soils. 1. The Effect of Soil Type, Water Content and Applied Pressure on Uni-axial Compaction," Soil Tillage \& Research, Vol. 41, 1977, pp. 53-73. doi:10.1016/S0167-1987(96)01084-7

[12] D. D. Fritton, “An Improved Empirical Equation for Uniaxial Soil Compression for a Wide Range of Applied
Stresses," Soil Science Society of America Journal, Vol. 65, 2001, pp. 678-684. doi:10.2136/sssaj2001.653678x

[13] J. O. Ohu, G. S. V. Raghavan, E. McKyes and G. Mehuys, "Shear Strength Prediction of Compacted Soils with Varying added Organic Matter Contents," Transactions of the American Society of Agricultural Engineers, Vol. 29, No. 2, 1986, pp. 251-255.

[14] A. P. Onwualu and U. G. N. Anazodo, "Soil Compaction Effect on Maize Production under Various Tillage Methods in a Derived Savanna Zone of Nigeria,” Soil \& Tillage Research, Vol. 14, No. 2, 1989, pp. 99-114. doi:10.1016/0167-1987(89)90025-1

[15] T. W. Lambe, “Soil Testing for Engineers,” John Wiley, New York, 1951.

[16] A. Walkley and I. A. Black, “An Examination of the Different Methods for Determining Soil Organic Matter and a Proposed Modification of the Chromic Acid Titration Method," Soil Science, Vol. 37, No. 1, 1934, pp. 29-38. doi:10.1097/00010694-193401000-00003

[17] M. Krzic, C. E. Bulmer, F. Teste, L. Dampier and S. Rahman, "Soil properties Influencing Comppactability of Forest Soils in British Columbia," Canadian Journal of Science, Vol. 84, 2004, pp. 219-226. 